\title{
Defining rural, remote and isolated practices: the example of Slovenia
}

ROK PETROVCICA-F

Faculty of Medicine, University of Maribor, Slovenia

A - Study Design, B - Data Collection, C - Statistical Analysis, D - Data Interpretation, E - Manuscript Preparation,

$\mathbf{F}$ - Literature Search, $\mathbf{G}$ - Funds Collection

Summary There is no single definition of rural practice available. Definitions vary from one country to another, as countries differ in geography and have different health care systems with varying organizational specificities, even within the same country. In spite of increased urbanization and the specific health-related problems it brings with it, a large proportion of the world population still dwells in rural, remote, and isolated areas. In fact, there are many countries in the world with extensive rural areas. Rural areas are unique in organization, demographics, and infrastructure, and so are the specific health-related problems of people living in them. Healthcare in such areas is generally provided by general practitioners or by physicians specialized in family medicine. One of the basic challenges in rural health is defining which areas are rural and finding the characteristics that define "rural". There are several criteria and combinations of criteria that can be used to define rural areas. Their use mostly depends on the purpose for which the definition is used, and can thus vary from application to application. This paper addresses issues in rural family practice and criteria that may be used to define such practices. It also presents the use of criteria for defining rural practices in a small European country, on the example of Slovenia.

Key words: Slovenia, rural health, rural population, family practice.

Fam Med Prim Care Rev 2016; 18(3): 391-393

\section{Definition and specificity}

The proportion of the population living in rural areas is very diverse and depends on the continent, country, and region. The diversity of rural areas makes rural practices difficult to uniformly define [1-4]. The majority of literature on rural practices originates from Australia, Canada, and the United States $[1,5,6]$. The field of rural health is wellresearched in these countries and Australian researchers put great emphasis on the problems of health care worker distribution and isolation, health promotion, and money deficits in connection with rural areas [7-9]. These countries are geographically very different from European countries. In general, rural, and remote practices are defined as practices outside of urbanized areas, in which primary health care is provided by a small number of family physicians with limited access to specialists or advanced diagnostic equipment. Working in such an environment requires additional management skills and processes that are not normally required in urban areas [10].

Differences also arise in the use of the term "rural". Although this is an internationally used term, others do exist - for example, terms such as "remote", "peripheral", and "isolated". For the sake of uniform terminology, we employ the term "rural practice" in this paper.

To define rural practice, several criteria and various combinations of these criteria are used; these are listed below.

Number of inhabitants and population density. Number of inhabitants and population density are practical criteria, since they are used for statistical purposes to describe the distribution between rural and urban areas. On this basis, there are several definitions of rural areas used in the United States. The most common is the definition used by the Statistical Office. Urbanized areas are defined as those with inhabited cores of 50,000 or more inhabitants; suburbs are defined as areas adjacent to large towns of over 2,500 inhabitants. All other areas are referred to as rural areas [1].

Distance from the nearest hospital or health center or emergency unit. This criterion is decisive in the management of critically ill patients. However, it is not only the distance in kilometers that is important, but also the time needed to transport the patient. This depends on driving speed, road quality, and weather conditions. The Canadian Association of Emergency Physicians defines rural areas as those where health care is provided primarily by family physicians and where specialist treatment is limited. The distance criterion is then used to divide rural areas into three types: rural isolated, rural remote, and rural close areas, depending on the distance and time needed to transport a patient to a major regional hospital [11]

Professional isolation, opportunity to consult with other physicians, and additional requirements for education. Physicians in rural areas are more susceptible to professional isolation than those in urban areas. The smallest and most remote communities present particular challenges in terms of professional isolation and lack of professional support. Although the work itself may not differ much between the two very different geographical environments, the difficulty of work may vary. There is difficulty in cooperating with the local hospital, there is a lack of funding for the practice, and the practice is separated by a large distance from the more advanced care, referral, and specialist services. These are factors that affect professional isolation. Due to the lack of physicians in such areas, rural doctors provide a large amount of on-call and overtime duties. Despite the progress of information technology, physicians in rural areas are still deprived of conferences, workshops, and courses, because of the distance from places where this education takes place [10]. 
Professional isolation affects patient safety. Apart from the reasons mention above, there is also less opportunity to consult with other physicians. This generates specific situations that can be dangerous for patients [12]. Wholey et al. also noted differences in professional errors between rural and urban hospital environment [13].

Social and economic status of the rural areas. The term "rural" is usually associated with an older population, more sparsely populated areas, and lower socioeconomic conditions. The income of the population often depends on a single industrial sector that dominates the area [1]. The population in rural areas tends to decline, mainly due to the emigration of the younger population. Additionally, much of the rural population commutes. There are seasonal population movements, with an increase during the tourist season [3]. In rural areas, the population is aging, which is associated with the aging of the population in general. The GDP in rural areas is smaller than in the country in general. The economy is based on primary (agriculture, forestry, and fishery) and secondary (industry, construction, and craft) sectors [4].

Accessibility of social, cultural and educational infrastructure, employment opportunities for partners. Rural areas are characterized by a low number of cultural and social institutions, such as theatres, cinemas, art galleries, and libraries. They are also limited in the number and proximity of educational institutions, such as primary schools, colleges, and universities. Access to facilities in another location is often time consuming and expensive. This is also linked to fewer employment opportunities for partners and for children's education. Single physicians also have fewer opportunities to meet partners in such an environment [10].

Health status of the rural population. Globally speaking, the state of health of the rural population is worse that than of the urban population. In the European Union, between $5 \%$ and $41.5 \%$ of the population of rural areas works in a primary sector. This sector suffers from a large number of workplace injuries. There is also increased number of accidents involving vehicles and more suicides [4]. In rural areas, a large number of injuries occur in work in primary sector industries. There are also an increasing number of zoonoses, such as leptospirosis and diseases transmitted by mosquitoes and ticks. The rural population enjoys more alcohol and cigarettes [5].

Patients in rural areas have less choice of physicians [12]. In 2004, 9.4\% of all Canadian physicians dealt with $21.1 \%$ of the Canadian rural population [6].

\section{Definition of rural by WHO and EURIPA}

The World Health Organization (WHO), in a report named "Rural poverty and health systems in the WHO European region", emphasizes that, for international comparison, the Organisation for Economic Co-operation and Development (OECD) regional typology permits regions to be classified as predominantly rural, intermediate, and predominantly urban. These classifications are based on criteria reflecting population density, regional population percent- age living in rural communities, and the presence of large urban centers in a region. On EU levels, the definitions developed by the EC Directorate General for Regional Policy build on the OECD definition by considering accessibility to services [14].

The European Rural and Isolated Practitioners Association (EURIPA) uses a grading system from the UK Department for Environmental, Food, and Rural Affairs to define rural areas based on settlement type:

- $\quad$ Significantly Rural: districts with more than 37,000 people, or more than $26 \%$ of their population in rural settlements and larger market towns;

- Rural 50: districts with at least 50\% but less than $80 \%$ of their population in rural settlements and larger market towns;

- Rural 80: districts with at least $80 \%$ of their population in rural settlements and larger market towns [15].

\section{Definition of rural practice in Slovenia}

Slovenia is a central European country with a population of 2,046,976 as of 1 January, 2010. Population density is 101.1 inhabitants per square kilometer [16]. There is no official definition of rural practice in Slovenia, but the most commonly used definition is that of the rural and remote section of the Family Medicine Society:

Rural and remote family practices in Slovenia are those practices located:

a) in rural areas, outside larger settlements (in places with fewer than 5,000 inhabitants and places that are at least $15 \mathrm{~km}$ from major cities); or

b) in a very rural, agricultural, mountainous, or sparsely populated area; or

c) in remote areas (> $20 \mathrm{~km}$ from the nearest hospital or emergency unit).

Many physicians in rural practices work in professional isolation; this term refers to the situation of a physician working alone or with a single family medicine physician within $10 \mathrm{~km}$. The practices where such physicians work may be branches of a larger health institution with its headquarters in a neighboring town, private practices, or independent health professionals [17].

\section{Conclusion}

No definition or criterion of rural practice is universal or covers all practices that could be classified as rural, especially when we consider different countries. The definition also depends on the purpose and need to which it applies [1]. Therefore, in deciding whether a certain practice is rural or not, we need to consider several criteria specific to a particular country and to take into account each practice separately.

\section{Acknowledgments}

I express my great gratitude to Professor Janko Kersnik, $\mathrm{MD}, \mathrm{MSc}$, PhD, for his mentorship.

Source of funding: This work was funded by the author.

Conflict of interest: The author declares no conflict of interests.

\section{References}

1. Hart G, Larson E, Lishner D. Rural Definitions for Health Policy and Research. Am J Public Health 2005; 95(7): $1149-1155$.

2. Buzeti T, Blenkuš M, eds. Neenakosti v zdravju. Ljubljana: Inštitut za varovanje zdravja Republike Slovenije; 2011. 
3. United Nations. World Urbanization Prospects, the 2011 Revision 2011 [cited 04.02.2015]. Available from URL: http://esa. un.org/unpd/wup/index.html.

4. European Union. Rural Development in the European Union - Statistical and economic information. 2013 [cited 04.02.2015]. Available from URL: http://ec.europa.eu/agriculture/statistics/rural-development/.

5. Strasser R. Rural health around the world: challenges and solutions. Fam Pract 2003; 20(4): 457-463.

6. Pong R, Pitblado R. Geographic distribution of physicians in Canada. 2005 [cited 04.02.2015]. Available from URL: https:// secure.cihi.ca/free_products/Geographic_Distribution_of_Physicians_FINAL_e.pdf.

7. Keane S, Smith T, Lincoln M, et al. Survey of the rural allied health workforce in New South Wales to inform recruitment and retention. Aust J Rural Health 2011; 19(1): 38-41.

8. Chisholm M, Russell D, Humphreys J. Measuring rural allied health workforce turnover and retention: what are the patterns, determinants and costs? Aust J Rural Health 2011; 19(2): 81-88.

9. Smith KB, Humphreys JS, Wilson MGA. Addressing the health disadvantage of rural populations: how does epidemiological evidence inform rural health policies and research? Aust J Rural Health 2008; 16(2): 56-66.

10. Rourke J. In search of a definition of "rural". CJRM 1999; 2(3): 113.

11. CAEP. The Management of Rural, Remote and Isolated Emergency Health Care Facilities in Canada. 2014 [cited 04.02.2015]. Available from URL: http://caep.ca/resources/position-statements-and-guidelines/recommendations-management-ruralremote-and-isolated--5.

12. Corbett $\mathrm{S}$. Literature review to examine the impact of isolation and rurality on patient safety in primary health care settings in Europe. 2012 [cited 04.02.2015]. Available from URL: http://euripa.woncaeurope.org/sites/euripa/files/documents/Literature\%20review\%20final.pdf.

13. Wholey D, Moscovice I, Hietpas T, et al. The environmental context of patient safety and medical errors. J Rural Health 2004; 20(4): 304-313.

14. Corbett $\mathrm{S}$. Literature review to examine the impact of isolation and rurality on patient safety in primary health care settings in Europe. 2012 [cited 31.07.2015]. Avaliable form URL: http://euripa.woncaeurope.org/sites/euripa/files/documents/Literature\%20review\%20final.pdf.

15. WHO: Rural poverty and health systems in the WHO European Region. 2010. [cited 31.07. 2015]. Avaliable from URL: http:// www.euro.who.int/en/publications/abstracts/rural-poverty-and-health-systems-in-the-who-european-region.

16. GOV. About Slovenia. 2013 [cited 04.02.2015]. Available from URL: http://www.vlada.si/en/about_slovenia/: http://www. vlada.si/en/about_slovenia/.

17. Kersnik J, Klemenc KZ. Sekcija zdravnikov družinske medicine v podeželskih in odmaknjenih ambulantah. ISIS 2013; 22(7): $16-17$.

Address for correspondence:

Rok Petrovcic, MD

Faculty of Medicine

University of Maribor

Slovenia

Tel.: +38631215650

E-mail: rok.5rovcic@gmail.com

Received: 16.07.2016

Revised: 16.08.2016

Accepted: 17.08.2016 